\title{
Isolated splenic vein thrombosis: An unusual cause and review of the literature
}

\author{
Seyfettin Köklü $M D^{1}$, Aydın Köksal $M D^{1}$, Ömer Faruk Yolcu $M D^{1}$, Gürsel Bayram $M D^{1}$, Zişan Sakaoğulları $M D^{2}$, \\ Kemal Arda $\mathrm{MD}^{3}$, Burhan Şahin $\mathrm{MD}^{1}$
}

\begin{abstract}
S Köklü, A Köksal, Ö Faruk Yolcu, et al. Isolated splenic vein thrombosis: An unusual cause and review of the literature. Can J Gastroenterol 2004;18(3):173-174.

Isolated obstruction (mainly due to thrombosis) of the splenic vein usually results in left-sided portal hypertension and isolated fundal varice formation. This syndrome is a rare cause of gastrointestinal bleeding. Pancreatic diseases are among the most common etiologies of splenic vein obstruction. Renal disorders are rarely reported as a cause of splenic vein thrombosis. In the present article, a case of a 26-year-old woman with a perirenal abscess presenting with gastrointestinal bleeding as a complication of an isolated splenic vein thrombosis is described. The thrombosis could not be visualized with ultrasonography and angiography because of its extremely proximal localization. Fundal varices disappeared following splenectomy and nephrectomy. Follow-up at one year revealed the patient to be well both clinically and endoscopically.
\end{abstract}

Key Words: Fundal varice; Gastrointestinal bleeding; Perirenal abscess; Splenic vein; Thrombosis

\section{Une thrombose isolée de la veine splénique : Un cas inhabituel et une analyse bibli- ographique}

\begin{abstract}
D'ordinaire, une occlusion isolée (surtout causée par une thrombose) de la veine splénique entraîne une hypertension portale gauche et la formation de varices fundiques isolées. Ce syndrome est une rare cause d'hémorragie gastro intestinale. Les maladies pancréatiques font partie des étiologies les plus courantes d'occlusion de la veine splénique. Les troubles rénaux sont rarement responsables de telles thromboses. Dans le présent article est décrit le cas d'une femme de 26 ans ayant un abcès périrénal qui s'est présentée en raison d'une hémorragie gastro intestinale en complication d'une thrombose de la veine splénique. Il était impossible de voir la thrombose à l'échographie et à l'angiographie en raison de son emplacement extrêmement proximal. Les varices fundiques ont disparu après une splénectomie et une néphrectomie. Un suivi au bout d'un an a permis de constater que la patiente s'était remise, tant du point de vue clinique que du point de vue endoscopique.
\end{abstract}

Solated splenic vein thrombosis (SVT) is a rare clinical syndrome that may lead to bleeding from isolated gastric varices. Pancreatic disease is the most common etiology (1) and renal diseases including cyst and renal cell carcinoma have been described rarely $(2,3)$.

SVT should be considered in the presence of gastrointestinal bleeding when there is normal liver function and unexplained splenomegaly. It may be difficult to diagnose this entity endoscopically or radiologically (4). Extremely proximal occlusions may only be diagnosed intraoperatively.

Isolated SVT is one of the rare curable syndromes causing portal hypertension. While splenectomy is the choice of treatment for cases complicated by variceal bleeding, there is no consensus in the treatment of asymptomatic patients (5).

We present a patient with a perirenal abscess complicated by upper gastrointestinal bleeding from gastric varices secondary to isolated SVT. To our knowledge, this is the first reported case of a renal abscess as the cause of left-sided portal hypertension.

\section{CASE PRESENTATION}

A 26-year-old woman was referred to our hospital for upper gastrointestinal bleeding. She had a 10-day history of fever, left flank pain and dyspnea. She was first seen in a chest disease hospital and left-sided transudative pleural effusion was detected. At the second day of hospitalization she had hematemesis for which she was referred to our clinic. Physical examination demonstrated decreased breath sounds over the lower part of the left lung. She had a moderate splenomegaly on palpation. Her hemoglobin level was $81 \mathrm{~g} / \mathrm{L}$, hematocrit was $24.7 \%$, mean corpuscular volume was $81 \mathrm{fL}$, white blood cell count was $14.7 \times 10^{9} / \mathrm{L}$ and platelet count was $293 \times 10^{9} / \mathrm{L}$. Peripheral smear disclosed neutrophilia $(84 \%$ of the white blood cell count). Erythrocyte sedimentation rate was $122 \mathrm{~mm} / \mathrm{h}$. Biochemical tests (including liver enzymes) were normal except for a mild hypoalbuminemia. Left-sided pleural effusion was seen on chest radiography. Abdominal ultrasonography revealed splenomegaly, collaterals around the spleen, a heterogenous left kidney and a perirenal lesion that was considered to be an abscess formation. Computerized tomography showed splenomegaly and splenic infarct, varices around the fundus of the stomach and an approximately $5 \times 5 \mathrm{~cm}$ diameter, well-demarcated abscess formation in close proximity to the upper pole of left kidney (Figure 1). An upper gastrointestinal endoscopy revealed gastric varices and a normal esophagus. Selective intra-arterial digital splenic angiography was performed, showing a patent splenic and portal vein. A drainage tube was inserted to the perirenal abscess. Culture of the

${ }^{1}$ Department of Gastroenterology; ${ }^{2}$ Department of Pathology; and ${ }^{3}$ Department of Radiology, Türkiye Yüksek İhtisas Hospital, Ankara, Turkey

Correspondance: Dr Seyfettin Köklü, Söğ̈̈̈tözü caddesi, Atatepe sitesi, B2 blok, 34 / 28, Söğ̈̈tözü, Ankara Turkey.

Telephone +90-312-2863998, e-mail gskoklu@yahoo.com

Received for publication July 17, 2003. Accepted September 23, 2003 


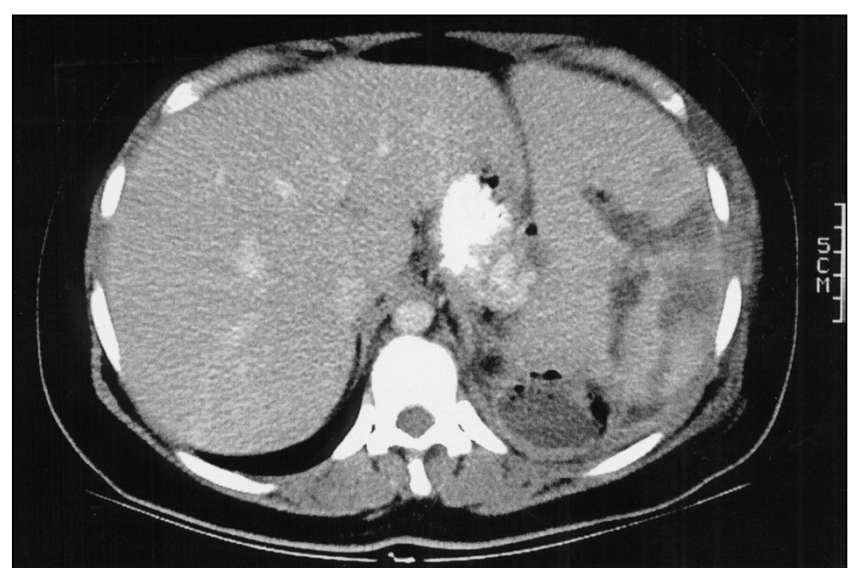

Figure 1) Computerized tomography showing left renal abscess and splenic infarct

drainage fluid isolated Enterococcus faecalis, and appropriate antibiotic treatment was started. With these findings, a diagnosis of splenic vein thrombosis secondary to renal abscess was reached, and a splenectomy was performed. The spleen was seen as large and congested intraoperatively. Short gastric veins were ligated. Left nephrectomy was also performed at the same time. The kidney was atrophic and contained multiple stones. Histopathological examination of the spleen revealed coagulation necrosis (Figure 2). The patient had no problem during postoperative follow-up and repeated endoscopy revealed the disappearance of the fundal varices.

\section{DISCUSSION}

Isolated obstruction (in most cases thrombosis) of the splenic vein causes left-sided portal hypertension. The majority of SVTs are the result of pancreatic pathologies, including acute and chronic pancreatitis, pancreatic pseudocyst, pancreatic tumour and abscesses (6). Other reported causes are traumas, umbilical vein catheterizations, lymphomas and sarcomas, retroperitoneal fibrosis, gastric surgeries, splenic artery aneurysms, myeloproliferative diseases and hereditary thrombocythemia (7). Although very rare, association of SVT and renal diseases including renal cell carcinomas and benign renal cysts have also been described in the literature $(2,3)$. One study reported an association of retroperitoneal tuberculous abscess and isolated SVT (8). Takeuchi et al (9) described a case of splenic vein occlusion due to tuberculous adenitis. To our knowledge, this is the first case of an association of renal abscess due to nephrolithiasis, secondary SVT and gastric variceal bleeding reported in English literature.

The mechanism of SVT in our patient appears to be secondary to the involvement of the splenic vein by the inflammatory process of a perirenal abscess. Pleural effusion was thought to be secondary to same-sided severe inflammation. SVT as the cause of left-sided pleural effusion, has been reported before (10). The mechanism of effusion formation in our patient may be due to the direct compression of posterior lymphatics by the perirenal abscess and filtration of abdominal fluid into pleura secondary to increased permeability caused by inflammation.

Gastrointestinal bleeding associated with SVT is due to varices that usually develop in short gastric and left gastroepiploic veins. Esophageal varices are less common than fundal varices because of blood drainage via the coronary vein.

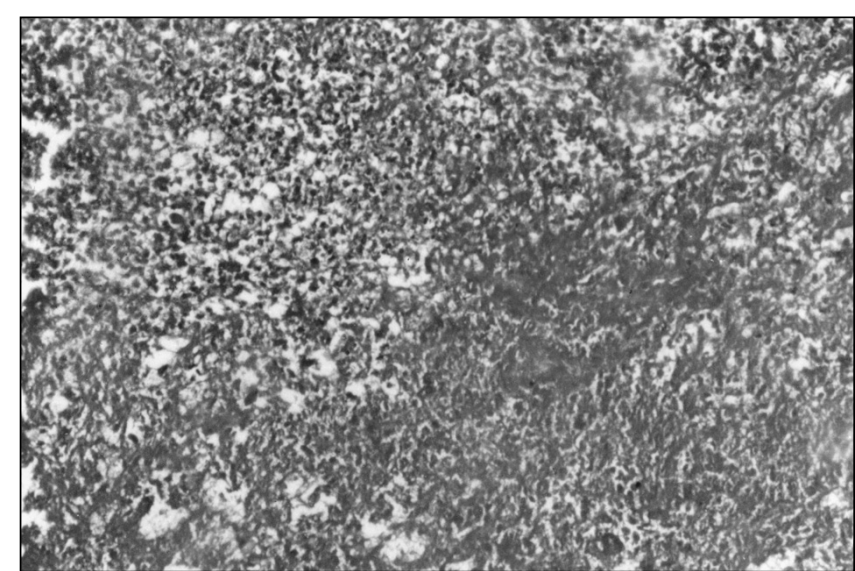

Figure 2) Coagulation necrosis of the spleen (Hematoxylin and eosin stain, magnification $\times 10$ )

The diagnosis of isolated SVT should be considered in any patient who presents with esophageal and/or fundal varices and normal liver function. It may be difficult to diagnose SVT (4). Even with angiography, the thrombosed splenic vein may be visualized as patent. SVT may not result in varice formation and it may be difficult to diagnose gastric varices either endoscopically or radiologically. The present case was unusual in that the splenic vein obstruction was quite proximal; therefore, the splenic vein was visualized as patent in ultrasound and angiography.

Splenectomy is the procedure of choice in the management of hemorrhage due to SVT. In selected cases, splenic arterial embolization may be tried (11). As yet, there are no verified data regarding the advantages of splenectomy in asymptomatic patients (5).

In conclusion, perirenal abscess may lead to isolated SVT and, ultimately, fundal varice formation. A diagnosis of SVT should be considered in patients presenting with normal liver functions and upper gastrointestinal bleeding due to gastric varices. The diagnosis may not be easy even with selective intra-arterial digital splenic angiography, which is accepted as the gold standard diagnostic test.

\section{REFERENCES}

1. Sakoforas GH, Sarr MG, Farley DR, Farnell MB. The significance of sinistral portal hypertension complicating chronic pancreatitis. Am J Surg 2000;179:129-33.

2. Hassan A, Ahmed M. Isolated splenic vein occlusion. JPMA 1982;32:79-80

3. Koehler RE. Splenic vein obstruction due to metastatic hypernephroma. Gastrointest Radiol 1981;6:365-70.

4. Illig KA, Spitzer RM, Oates TK. Optimal diagnosis of splenic vein thrombosis. Am Surg 1997;63:1005-6.

5. Zadrozny D. Left-side portal hypertension as a clinical problem. Wiad Lek 1999;52:494-9.

6. Smith TA, Brand EJ. Pancreatic cancer presenting as bleeding gastric varices. J Clin Gastroenterol 2001;32:444-7.

7. Glynn MJ. Isolated splenic vein thrombosis. Arch Surg 1986;121:723-5.

8. Nogueira Soriano JM, Diez GF, Pelaez DG, et al. Segmental portal hypertension due to a retroperitoneal abscess of tuberculous etiology. Rev Esp Enferm Dig 1991;79:211-3.

9. Takeuchi H, Suzuki M, Unno M, et al. Splenic vein occlusion secondary to tuberculous lymphadenitis at the splenic hilum. Surg Today 2000;30:383-5.

10. Warren MS, Gibbons RB. Left-sided pleural effusion secondary to splenic vein thrombosis. A previously unrecognized relationship. Chest 1991;100:574-5.

11. Sato T, Yamazaki K, Toyota J, et al. Gastric varices with splenic vein occlusion treated by splenic arterial embolization. J Gastroenterol 2000;35:290-5. 


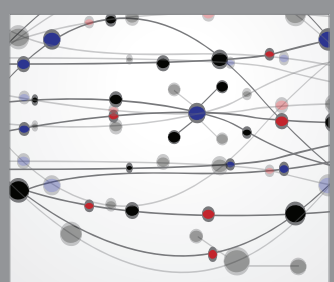

The Scientific World Journal
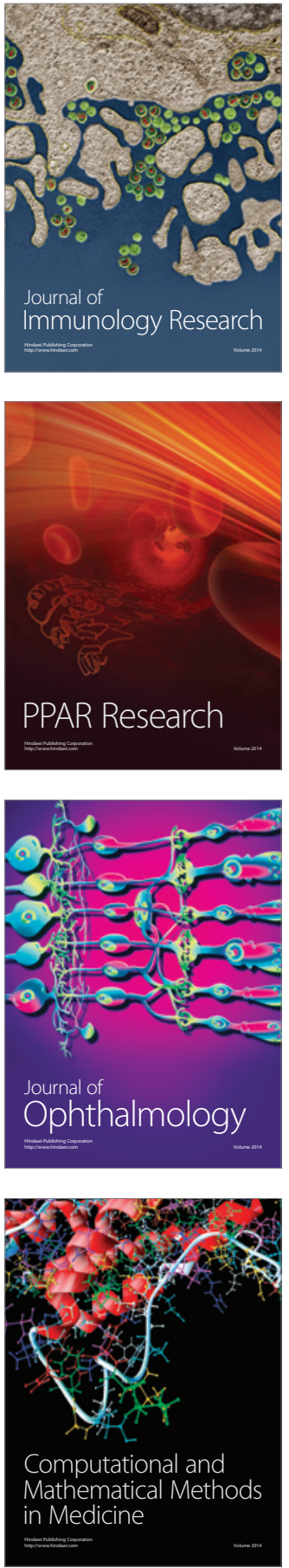

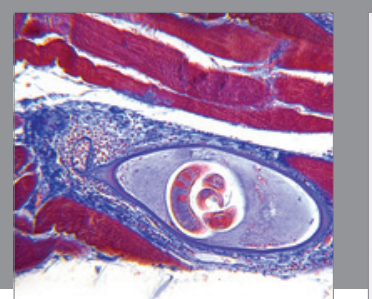

Gastroenterology Research and Practice

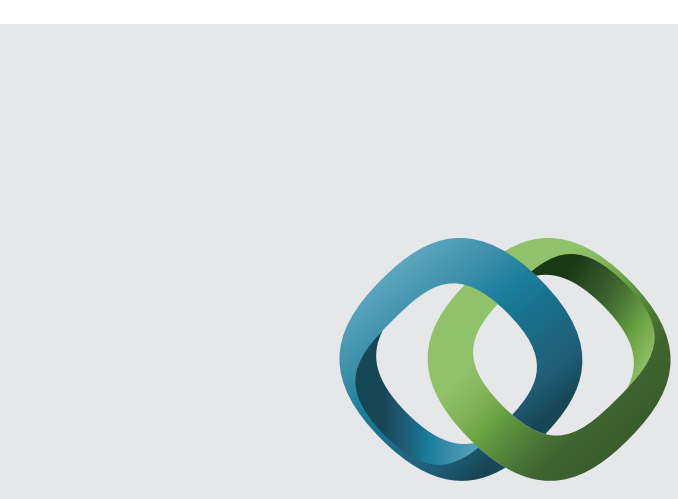

\section{Hindawi}

Submit your manuscripts at

http://www.hindawi.com
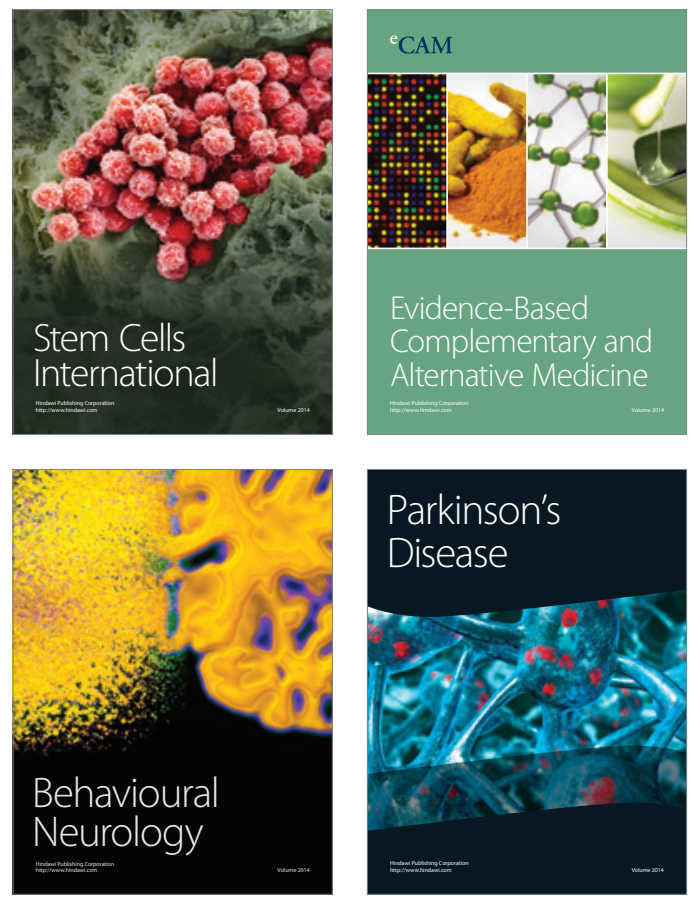
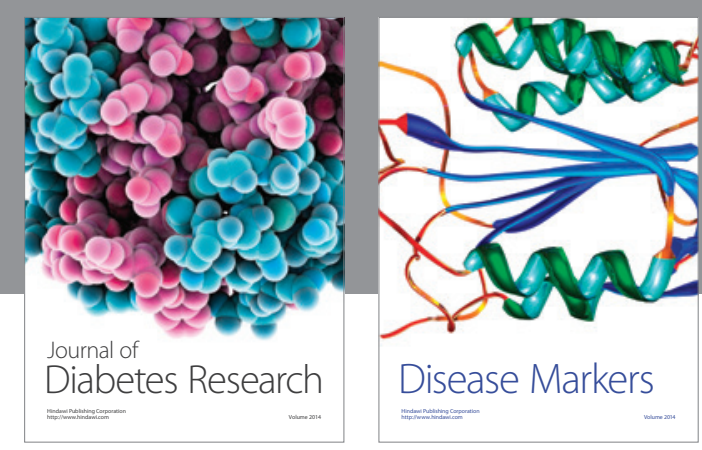

Disease Markers
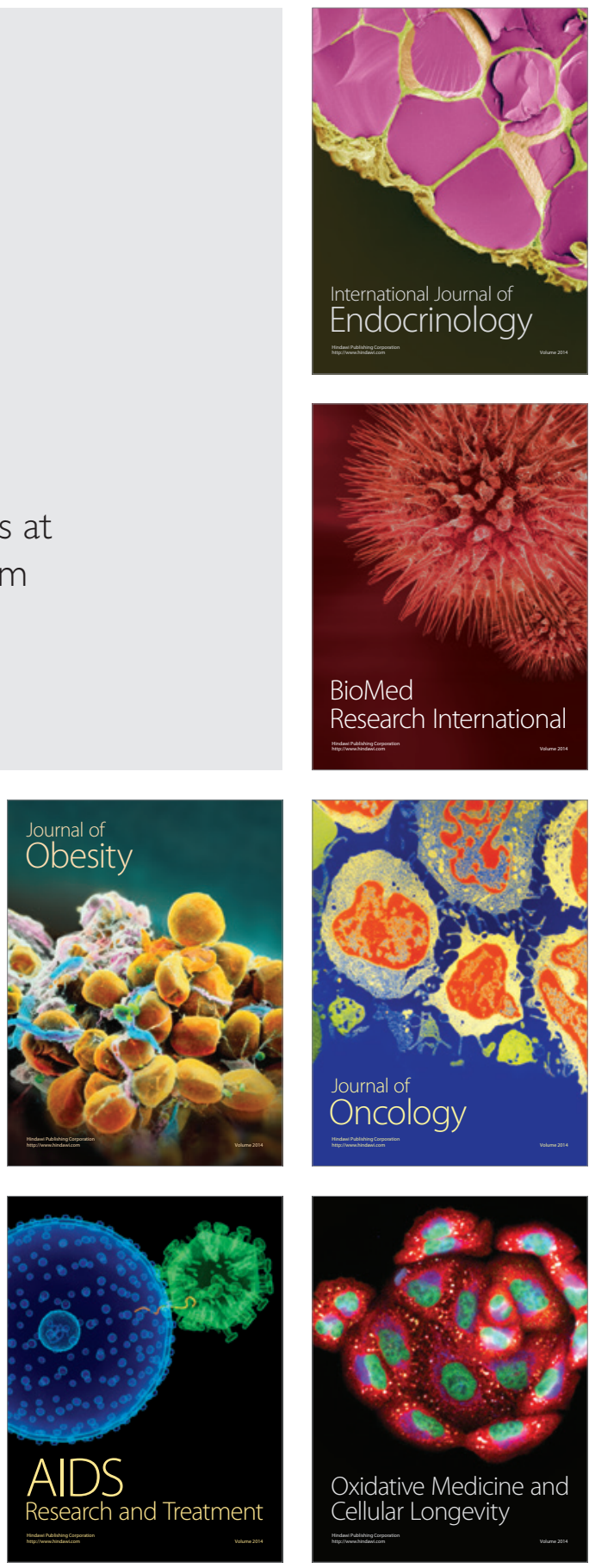